\title{
Research on flaw and strategies in scientific research management system in Chinese universities
}

\author{
Shupeng $\mathrm{Xu}^{1}$,Jianqun $\mathrm{Sun}^{2}$ \\ ${ }^{1}$ Suzhou University of Science and Technology, Suzhou Jiangsu, 215010, China \\ ${ }^{2}$ Soochow University, Suzhou Jiangsu, 215010, China
}

Keywords: Scientific research management, College and universities, System flaw, Improve measures.

\begin{abstract}
Chinese social economy, various social infrastructure constructions are tending to be well established and every walk of social life has greatly improved. Education and scientific research activities in colleges and universities have made great progress under the strategy of technology intensification. But inconsistent with the rapid development of scientific research, scientific research management system in Chinese universities at present is not consummated well, which has brought about some impact on the further development of scientific research cause. Thus, to further promote the scientific research management reform in universities, it is urgently necessary to make in-depth exploration on the management system so as to lay solid foundation for the deepening and implementation of scientific research reform.
\end{abstract}

\section{Introduction}

Scientific research management system is the substantial safeguard for Chinese universities to guarantee their scientific research work to be smoothly carried out. Construction of good scientific research management system can not only create good environment for the development of college scientific research career but can also promote the equal competition between different scientific research projects so that scientific research management work can be standardized and carried out orderly and to lay foundation for the deepening development of college scientific research work.

\section{The necessity for colleges and universities to strengthen scientific research management system}

The establishment of scientific research management in colleges and universities has positive influence on improving scientific research management level and creating good working environment for scientific research. It can even play important role in improving the scientific research efficiency in colleges and universities to promote the overall scientific research level in China. Therefore, it has relevant realistic significance for colleges and universities to pay more attention to scientific research work with the hope to establish a sound scientific research management system to provide support for the optimization of scientific research work [1].

At this stage, under the influence of the increase of college scientific research work and imperfect of management system, some problems have appeared in college scientific research work. For example, legal consciousness becomes dim, emphasize quantity instead of quality, and focus on scientific research scores but ignore substantial issues in scientific research. These problems have brought about negative impact on the formation of college scientific research atmosphere and attracted extensive attention in the academic circles. Therefore, it is very necessary to establish a sound scientific research management system to provide support for good operation and standardized development of scientific research work so as to help college scientific research work can obtain better development in the new era. 
Some flaws existing in the scientific research management system of Chinese colleges and universities.

With the implementation of technology power strategy in China, scientific research cause in Chinese colleges and universities have gained great expansion and made great progress under the support of national finance and human resource administrative depart. But with the increase of national scientific research investment and financial investment, followed are some problems in college scientific research management. There emerge a series of corruptions and degeneration in college scientific research administrative departments during the mismanagement. This has had important impact on the positive development of college scientific research and even limited the advancement of scientific research work [2]. It can be seen that, there still exist serious flaws in Chinese college scientific research management system, which is harmful for the positive operation of management work but also leads to the spreading of corruption in college scientific research field and will bring about severe restrictive effect on the development of scientific research work. Therefore, to ensure that colleges further implement the strategies of strengthening the country through talents and technology, it is necessary to make analysis on existing problems in scientific research management system. Then explore causes of flaws, settle down detailed problems and provide suggestions on the system perfection so as to provide guarantee for the optimized execution of scientific research with a sound management system.

\section{Causes of flaws on Chinese colleges scientific research management system}

\section{Current college scientific research management system is loose}

The loose scientific research management system in current college is the main reason of management flaws and embezzlement of scientific research funds. It leads to poor restriction of scientific research and management staffs so that when neglecting management, it is hard to find out the scientific research funds embezzled. Especially the release of scientific research funds from the country lack uniformity so that is hard to make an in-depth investigation and analysis on where those college scientific research funds had gone. Finally it leads to some management staffs' corruption through making use of management system flaws driven by benefits. This has seriously impacted the optimized implementation of scientific research work.

\section{Too many Items of scientific research staff expenditures}

Currently a hidden danger in scientific research management system is that there are too many items of expenditures of staffs who working on scientific research in Chinese colleges and universities. This has severely limited the smooth execution of scientific research management work. Seeing from the financial expenditures of Chinese college scientific research staffs, there are a large amount of scientific research staffs in different types and the scientific research projects are huge. But since the construction of scientific research management in China is not completed, the scientific research management effect is poor so that some scientific research staffs with special identities can randomly make up scientific research projects, set up items of expenditures, and seek excessive profits from scientific research work. This has not only restricted the optimized implementation of scientific research work but also brought about negative impact on the formation of good scientific research atmosphere in colleges and universities [3].

\section{Salary of college scientific research staffs is poor}

Among all flaws existing in college scientific research management system, scientific research staffs' poor salary is an important content. In recent years, although college scientific research work has been developed to a certain degree, actually the salaries of scientific research staffs have not been significantly improved. Some scientific research staffs have made huge contributions but never get paid back they have deserved from the country and society. With time passing by, these workers will be sluggish and even commit corruption in their work to severely restrict the in-depth development of college scientific research work. Therefore, to make up the loopholes in scientific research 
management system, scientific research staffs' salaries should be improved so as to make sure what they have given can obtain corresponding payoff.

\section{Measurements to further make up loopholes in current college scientific research management system}

\section{Basic tasks for current construction of scientific research management system}

To further promote the rapid development of college scientific research work, to establish sound scientific research management system and to provide relevant assistance for sustainable and healthy development of college scientific research work, it requires us to make a comprehensive and in-depth analysis on college scientific research management system for further improving the scientific function and pertinence management system so as to provide some support for further development of promoting college scientific research work.

Firstly, scientific research evaluation system can provide correct guidance for scientific research work. In current stage, most colleges in China have established relevant scientific research performance evaluation system based on the scientific research work requirement to make quantitative assessment on scientific research workers' achievements. They also provide relevant allowance and subsidies according to the evaluation results and select whether they can get promoted. But this kind of evaluation system makes most teachers put their work focus on publishing research paper and wining research projects for job promotion and salary increase. But the scientific research quality of the whole college cannot be improved and it has severely impacted the development of college scientific research cause. Therefore, it is necessary to establish more scientific evaluation system to correctly guide scientific research staffs' work and help them truly combine education with scientific research so that scientific research can get sustainable and healthy development in the future [4].

Secondly, establish more reasonable scientific research incentive system. Regarding the problem that Chinese colleges pay attention to quantity but quality, a sound scientific incentive system should be established to further help them attach more importance to scientific research quality. Then help them truly promote the sustainable and healthy development and create conditions for the perfection of college scientific research management system based on high level scientific research achievement. So in detailed operation, colleges can start setting up incentive system on particle high level scientific research staffs and encourage them to make further exploration in scientific research so that the college scientific research work quality can be significantly improved and make contribution for the realization of the strategy of strengthening China through science and technology.

At last, reform scientific payoffs reward system. Scientific research work in college is important function to provide service for the society which can have great influence on the development of the social technology. So to encourage various experts in colleges to actively get into scientific research work and promote further development of college scientific research work, scientific payoffs reward system should be emphases to improve the activity of scientific research staffs on scientific development. Regarding detailed operation, colleges can set up relevant reward system according their practical situation to make correct guidance for the reward work to be carried out orderly. On the other hand, they should pay great attention to the promotion of scientific payoffs to make sure the scientific achievement can truly be applied to social lives exerting the effect of college scientific research achievements utmost.

\section{Measurements proposed based on the flaws in Chinese college scientific research management system}

Regarding the flaws in Chinese college scientific research management system, to further improve the current situation in college scientific research management, propose relevant compensation measurements based on the reasons of flaws to provide support and reference to complete and perfect 
college scientific research management system. Specifically, it can be done from three aspects as below:

Firstly, make comprehensive analysis and screening on problems existing in college scientific research management and find out flaws and detailed reasons. Then discover the measurements to improve college scientific research management system so as to improve the orderliness and standardization of management work. Only in this way can the function of college scientific research management be fully exerted so as to ensure college scientific research work can operate orderly[5]. Meanwhile, since the construction of college scientific research management system involves many aspects, it will bring about huge impact once adjusting the management system. Thus during the process of perfecting management system, too much modification should be avoided. Instead, supplement and perfect the management system according the flaws and reasons to gradually improve the completeness and applicability of management system so as to make sure college scientific research management system can reasonably manage college scientific research and provide solid guarantee for sustainable and healthy development of college scientific research work.

Secondly, during the construction of college scientific research management system, properly penetrate the concept of laws and regulations. To comprehensively and accurately understand the condition of Chinese college scientific research management, especially to make reasonable control of college scientific research funds so that each fund can be applied to the most suitable work, the country and relevant departments should strengthen relevant department management during the process of perfecting management system based on the practical situation of college scientific research management work. Special financial department should be in charge of college scientific research funds to guarantee the funds can be scientifically used. Meanwhile, based on the corruptions existing in college scientific research management work, some concepts of laws and regulations should be properly penetrated during the process of constructing management system. Combine system management with laws and regulations, and manage working staffs scientifically governed by the laws. Only in this way can scientific research personnel working activity be improved so that they can strictly restrain themselves in various scientific research work and promote the scientific research work to be successfully carried out. At the same time, during the process of constructing management system, integration of laws and regulations can help colleges to create good scientific research environment so that scientific research personnel can work in positive and healthy atmosphere with a positive attitude to complete various scientific research work so as to truly promote college scientific research work can obtain further development with the support of good regulations.

At last, further improve the salary of Chinese college scientific research personnel. To get further development, the negative impact of scientific research management system loopholes should be reduced. In addition, pay attention to increase salaries of scientific research personnel and make sure their devotion can be paid off equally. Only in this way can the function of college scientific research management system can be exerted to the largest degree so as to provide relevant guarantee for the optimized implementation of college scientific research work. Meanwhile, further increasing salaries of scientific research personnel can intensify their working activity and their sense of identity for the college so as to help schools to win in the fierce talent competition. Only in this way, the danger of management system loopholes can be minimized through starting from the ideological understanding and professional morality of working staffs to avoid the management system loopholes producing more harms to college scientific research work and to help college scientific research management work quality be significantly intensified.

\section{Conclusion}

Based on above analysis, we can find that there exist some problems in Chinese college scientific research management system, which have seriously influence sustainable and healthy development of college scientific work. Therefore, to help college scientific research work to make bigger progress in the new era, scientific research management system construction should be strengthened through gradually making up loopholes existing in current college scientific research management system to 
improve the scientificity and feasibility of scientific research management system so as to provide solid guarantee for the implementation of college scientific research work and truly promote college to obtain more scientific research achievements in the new era.

\section{Reference}

[1] Chen Huashui. Analysis on behaviors of government, enterprise, and laborers in constructing harmonious labor relationship, Journal of University of Electronic Science and Technology of China (Social Science Edition),2014(6):57-62.

[2] Bie Ronghai. Current situation and its optimization of college scientific research management system under the perspective of financial performance, Hubei Social Sciences,2013(2):163-165.

[3] Qiu XInyue. Exploration of Chinese college scientific research funds management system under the vision of law, Anhui University,2015.

[4] Zhu Chunyan. Research on college research talent management system innovation, Science \& Technology Progress and Policy,2012,29(11):100-102.

[5] Lai Ke. Research on college scientific research funds usage and management, Southwest University,2015.

[6] Li Yongning. Thinking on several problems of strengthening college scientific research funds management, China Township Enterprises Accounting,2012(5):88-89. 